\title{
MUDANÇAS E DESAFIOS PARA 0 DIREITO COOPERATIVO NO BRASIL
}

\section{Renato Lopes Becho}

Graduado em Direito pela Universidade Federal de Minas Gerais - UFMG

Especialista em Cooperativismo pela Universidade do Vale do Rio dos Sinos - UNISINOS/RS

Mestre, doutor e professor de Direito Tributário na Pontifícia Universidade Católica de

São Paulo - PUC/SP

Livre-docente em Direito Tributário pela Universidade de São Paulo - USP

Estágio pós-doutoral no King's College de Londres. Juiz federal em São Paulo/SP

\section{RESUMO}

0 texto, de natureza descritiva, pretende demonstrar os pontos mais críticos do Direito Cooperativo no Brasil. Não há a pretensão de esgotar o tema mas, tão somente situar o leitor estrangeiro sobre o momento histórico vivido pelo Brasil. 0 texto será dividido em quatro capítulo, sendo o primeiro tratará dos desafios democráticos aos cooperativismo brasileiro, 0 segundo capítulo abordará as propostas legislativas em debate no Congresso Nacional e que, em futuro próximo poderá alterar o Direito Cooperativo, o terceiro capítulo indicará os temas principais em discussão no Poder Judiciário, demonstrando que as questões tributárias são as mais candentes no Brasil e, o quarto e último capítulo tratará da ausência de uma doutrina jurídica atual, capaz de responder aos desafios no novo século.

PALAVRAS CHAVE: Cooperativismo, Direito Cooperativo, Direito Brasileiro, Ato Cooperativo, Tributação.

CLAVES ECONLIT / ECONLIT DESCRIPTORS: J54, N00; P32.

Cómo citar este artículo/How to cite this article: LOPES BECHO, R.: "Mudanças e desafios para o direito cooperativo no Brasil", CIRIEC-España, Revista Jurídica de Economía Social y Cooperativa, no 39, 2021, pp. 327-340. DOI: 10.7203/CIRIEC-JUR.39.21961 


\section{CHANGES AND CHALLENGES FOR COOPERATIVE LAW IN BRAZIL}

\section{EXPANDED ABSTRACT}

Cooperatives are societies with their own nature and structure, with social and economic utility. They are social economy entrepreneurs who must follow cooperative principles and values such as mutuality and concern with the community and with cooperation between cooperatives.

International organizations (ICA, UN, ILO) encourage countries to reaffirm the principles and values of the ICA/1995 Declaration and to promote cooperatives (Recommendation 193/ ILO). In the regional spheres (European Union and MERCOSUL), there is also concern about spreading cooperativism. The conferences and meetings of agents specialized in cooperatives in Ibero-America suggest the harmonization of laws, public policies and the regional integration of cooperatives, with the legal recognition of MERCOSUR cooperatives.

The policies involve actions through which cooperatives are able to carry out their activities, meet the demands of the market and their members, and obtain space in the competitive market. Therefore, it is recommended that cooperatives be promoted and protected at regional levels, with instruments and programs for integration between different countries and without obstacles to their expansion.

The model of insertion of the cooperative society in Latin American countries comes from the European experience and has had a heterogeneous evolution, with different origins and degrees of state intervention, in addition to the lack of access to credit. Taking into account the economic importance that cooperatives have in the region, institutional mechanisms are still being sought with the task of consolidating and strengthening the cooperative model, as well as the development of cooperatives in the national and regional market.

In Brazil, cooperatives are still governed by Law 5,764/1971 and by the Civil Code (with the 2002 reform). They are conceptualized as a society of people, of their own form and nature, of a civil nature, characterized by the principles and values of the ICA. Currently, there are also special laws in Brazil, such as the law on social cooperatives (law 9,868/99), the law on work cooperatives (law 12,690/12) and the law on credit cooperatives (Complementary Law $130 / 09$ ) that improve the concept of society of people, moving away from the commercial nature of cooperative societies. 
By express provision of the law, cooperatives are equated to non-business companies, that is, simple companies, and are not subject to the commercial bankruptcy regime. It is clear in Brazil that the legal regime of cooperatives is old and conventional, disconnected from the economic reality of the market and also that it is necessary to make changes to improve corporate aspects and the economic regime of cooperatives.

In addition, there are social and cultural obstacles against the cooperative in Brazil, with a lack of knowledge of the community and the judiciary about the characteristics of cooperatives, localized problems in the management of cooperatives and in the relationship with cooperatives, difficulties of capitalization and credit for the cooperative and the prejudice that exists about this type of company. These aspects add to the institutional setting that is difficult for Brazilian businessmen, with the disregard of the legal personality without criteria, the bureaucracy, the fiscal costs and charges of the employment relationship.

Two general bills on cooperatives are being processed in the National Congress (Bill Nos. 153/07 and 03/07). Recently, a new standard of the Accounting Committee (ICP 14) has come into force with provision for financial instruments for cooperatives. Despite establishing changes in the matter, concerns about the adequacy of the rules in view of the nature and needs of cooperatives persist.

Despite the legislation not following the real legal and economic nature of cooperatives, they have great importance for the Brazilian economy. By virtue of the lack of support, in reality cooperatives are associated with other companies or even remain economically unviable.

This 50-year time lapse represents a generation gap -two generations more specifically- of jurists who no longer think about cooperativism. In other words, the legal knowledge of jurists from the 50s, 60s and 70s was not continued by the next generation and, consequently, was transmitted to the subsequent generation, which is why, currently, cooperative law is not debated.

This is reflected in the absence of scientific publications on cooperative law, organization of scientific events or even scientific associations. In class bodies, few actions are performed. At universities, the picture is the same, with very few exceptions, no professorships of cooperative law being offered. The research carried out by the graduate program is minimal, with few researchers or research groups dedicated to the topic, with little Brazilian participation in international organizations and associations.

In the absence of critical mass, the task of a major change in cooperative law remains for the next generations, and the current generation must overcome the difficulty of training new 
professionals in cooperative law. Overcoming structural issues such as the cooperative act or the mandatory intercooperation, uniqueness of representation, depends on the formation of a critical mass, which is yet to come.

For this, the role of universities in training the next generation of jurists is essential, either by resuming and rebuilding the existing knowledge on cooperative law - and introducing new themes, such as postgraduate studies with the discovery and organization of frontier themes that should be answered by the next generations, going through extension, working with existing cooperatives, in a process of double learning.

It is a long-term work that will demand a broad institutional articulation, involving political, economic and theoretical themes. This will challenge the government, civil society, companies, universities and research centers to form national, regional and international networks in pursuit of these common goals and make it possible to recover Cooperative Law in Latin America and respond to the new challenges of contemporary society. This will allow new challenges to be faced, such as the democratization of cooperatives and their expansion to the most popular spheres of society, which make up what is called in Latin America the solidarity economy, which rescues the old principles of Rochdale's cooperativism. These challenges will only be overcome with the interaction between theory -carried out by universities and research institutes- and practice, which involve court decisions, legal entities and social movements.

KEYWORDS: Cooperatives, Cooperative Law, Brazilian Law, Cooperative Act, Taxation. 


\section{SUMÁRIO}

Introdução - Desafios para as cooperativas brasileiras frente aos Poderes Públicos. I. Desafios com a fragilidade democrática atual. II. Desafio frente ao Congresso Nacional. II.1. Sobre a aguardada Lei Complementar Tributária para as sociedades cooperativas. II.2. Desafios para a Legislação Ordinária. III. Desafios no Poder Judiciário. IV. Modificações para a solidificação de uma doutrina jurídica cooperativista. Referências.

\section{Introduçáo - Desafios para as cooperativas brasileiras frente aos Poderes Públicos}

As cooperativas brasileiras vivem um momento de grandes desafios, alguns novos, outros não; alguns são devidos às mudanças sociais e afetam toda a sociedade, mas com particularidades para essas organizaçôes, enquanto outros desafios são decorrentes de especificidades próprias do cooperativismo. Pretendemos abordar tanto uns quanto outros. Além disso, novos desafios globais se apresentam ao cooperativismo brasileiro, como as cooperativas de plataforma ou, as cooperativas binacionais.

Muito destes problemas extrapolam o campo jurídico e encontram sua origem na ausência de recursos humanos especializados em direito cooperativo no território brasileiro, fato este que nos leva a acreditar em soluçóes de longo prazo, especialmente a formação de uma nova geração de juristas.

O texto é descritivo, organizado como um ensaio sobre as questóes futuras do direito cooperativo no Brasil, evitando muitas vezes os rigorismos acadêmicos que muitas vezes empobrecem o debate.

\section{Desafios com a fragilidade democrática atual}

A democracia brasileira tem sofrido severos ataques nos últimos anos, que fizeram com que os sinais de alerta fossem acesos de modo significativo. Acaso nossa democracia não sobreviva à atual fase, o cooperativismo deve estar atento para as ameaças que ele provavelmente enfrentará. Senão vejamos.

$\mathrm{Na}$ história do Brasil, nossos períodos democráticos foram rompidos com frequência. Nos tornamos independentes de Portugal em 1822, sendo um marco mais político do que jurídico a Constituição Imperial brasileira que se seguiu $(1824)^{1}$. Em

1. O texto da Constituição Política do Império do Brasil, de 1824, está disponível em http://www.planalto.gov. br/ccivil_03/constituicao/constituicao24.htm 
1889 o período monárquico foi encerrado com um golpe de Estado, seguido pela Constituição republicana de 1891, que fortaleceu o constitucionalismo nacional, conforme ensinamento de um de nossos maiores jus-publicistas, Pontes de Miranda ${ }^{2}$.

À Carta de 1891 sucederam as Constituições de 1934, 1937, 1946, 1967, $1969 \mathrm{e}$ 1988. A primeira delas (1891), como se percebe, foi a mais longeva até agora, sendo que as de 1946 e 1988 formularam, verdadeiramente, sociedades democráticas.

Tantas constituições são reflexo da fragilidade democrática brasileira, sendo que 2021 guardará, para dizer o mínimo, o maior estresse da Constituição de 1988 até o presente momento. Desde a posse, em $1^{\circ}$ de janeiro de 2019, o atual presidente da República, de extrema direita, atua contra o Direito, fazendo-nos lembrar, novamente, de Pontes de Miranda (1973, p. 04): “Quem perturba o direito ocidental, prepara guerra ou revolução". O ponto culminante foi a comemoração do Dia da Independência, 7 de Setembro, quando o presidente da República levou centenas de milhares de brasileiros às ruas para lhe corroborar o desejo de interferência direta no Congresso Nacional e no Supremo Tribunal Federal ${ }^{3}$. Entretanto, o mandatário não teve apoio suficiente para avançar além das palavras.

O leitor atento pode estar se perguntando o porquê de os riscos constitucionais serem um desafio para o cooperativismo brasileiro. De nossa parte, dois aspectos o justificam: o tratamento reservado às sociedades cooperativas pela Ditadura Militar, que governou o Brasil de 1964 a 1986. Se nesses 21 anos de suspensão democrática o Congresso Nacional aprovou uma razoável lei geral do cooperativismo (Lei no 5.764, de 1971), que continua regendo em grande medida tais sociedades e que contém balizas relevantíssimas, como os princípios que direcionam a atuação de todas as cooperativas, seguindo padrôes internacionais, também foram incluídos importantes elementos de controle governamental sobre as cooperativas. Tanto assim que a Constituição Federal de 1988 elencou, como um dos direitos e garantias fundamentais, a liberdade de associação e de participação em cooperativas, vedada a interferência estatal em seu funcionamento.

Ora, o regime antidemocrático exigia autorização prévia dos órgãos públicos de controle para a criação e funcionamento das cooperativas, permitindo até mesmo a dissolução de tais sociedades, por desejo dos governantes de então.

2. "A prática da Constituição de 1891, se não criou, no Brasil, o espírito constitucionalista, pois esse já nos vinha do trato de questóes levantadas no Império, fortaleceu-o, e precisou-o”. (MIRANDA, 1973, p. 07).

3. Tais acontecimentos, ocorridos há apenas dois meses, não puderam, ainda, chegar aos livros de Direito Constitucional ou de Ciência Política. Para consulta, sugerimos a busca pelos maiores jornais brasileiros: Folha de S. Paulo, O Estado de S. Paulo e O Globo. 
Por outro lado, o princípio democrático é caro ao cooperativismo, sendo o referencial das portas abertas, a fixação de que cada associado tem um voto e as decisóes em assembleias gerais ordinárias e extraordinárias indicam que tais sociedades florescem mais nas democracias e dos que ditaduras.

Acrescente-se ao quadro acima indicado o fato de que, nos Governos Militares, os dirigentes controlavam quais cooperativas eles queriam que fossem aprovadas ou não ${ }^{4}$. Os grupos mais conservadores, com destaques para os produtores rurais e os médicos, encontraram facilidade de desenvolvimento, enquanto grupos mais sociais, como outros prestadores de serviço, não experimentaram tanto apoio. Assim, as cooperativas de trabalho são mais relevantes hoje do que ontem.

Assim, se a Constituição Federal de 1988 não permanecer forte o suficiente para impedir a interferência do Poder Executivo federal no Congresso Nacional e no Supremo Tribunal Federal, a liberdade de associação e de participação em cooperativas, vedada a interferência estatal em seu funcionamento não estará mais garantida, colocando em risco quaisquer sociedades cooperativas.

\section{Desafio frente ao Congresso Nacional}

Neste tópico trataremos das questóes pendentes de uma atuação do Poder Legislativo brasileiro, especialmente em alguns pontos que estão previstos na Constituição Federal de 1988, mas, passados mais de trinta e três anos, ainda não foram debatidos e regulamentos pelo Congresso Nacional, omissão esta que causa sérios prejuízos para o desenvolvimento do cooperativismo brasileiro.

\section{II.1. Sobre a aguardada Lei Complementar Tributária para as sociedades cooperativas}

Permanecendo nossa atenção no Texto Constitucional de 1988, que é, por definição, a maior fonte do direito brasileiro atual, identificamos o segundo maior desafio

4. Art. 17. A cooperativa constituída na forma da legislação vigente apresentará ao respectivo órgáo executivo federal de controle, no Distrito Federal, Estados ou Territórios, ou ao órgão local para isso credenciado, dentro de 30 (trinta) dias da data da constituiçấo, para fins de autorização, requerimento acompanhado de 4 (quatro) vias do ato constitutivo, estatuto e lista nominativa, além de outros documentos considerados necessários. Art. 18. Verificada, no prazo máximo de 60 (sessenta) dias, a contar da data de entrada em seu protocolo, pelo respectivo órgáo executivo federal de controle ou órgáo local para isso credenciado, a existência de condiçóes de funcionamento da cooperativa em constituição, bem como a regularidade da documentaçáo apresentada, o órgão controlador devolverá, devidamente autenticadas, 2 (duas) vias à cooperativa, acompanhadas de documento dirigido à Junta Comercial do Estado, onde a entidade estiver sediada, comunicando a aprovaçáo do ato constitutivo da requerente. 
para as cooperativas a ausência, até os dias que correm, da lei complementar que disciplinará as normas gerais em matéria de tributação das cooperativas.

De fato, determina a Constituição Federal de 1988, o quanto segue:

Art. 146. Cabe à lei complementar:

I - dispor sobre conflitos de competência, em matéria tributária, entre a União, os Estados, o Distrito Federal e os Municípios;

II - regular as limitaçóes constitucionais ao poder de tributar;

III - estabelecer normas gerais em matéria de legislação tributária, especialmente sobre:

a) definição de tributos e de suas espécies, bem como, em relação aos impostos discriminados nesta Constituição, a dos respectivos fatos geradores, bases de cálculo e contribuintes;

b) obrigação, lançamento, crédito, prescrição e decadência tributários;

c) adequado tratamento tributário ao ato cooperativo praticado pelas sociedades cooperativas.

d) definição de tratamento diferenciado e favorecido para as microempresas e para as empresas de pequeno porte, inclusive regimes especiais ou simplificados no caso do imposto previsto no art. 155, II, das contribuiçóes previstas no art. 195, I e SS 12 e 13, e da contribuição a que se refere o art. 239.

O caput do dispositivo e seus incisos I e II já faziam parte, ainda que com redação um pouco diferente, da Constituição Federal de 1967, bem como da de 1969.

Sem entrar em detalhes que não são o foco do presente estudo (se competiria à lei complementar dispor sobre normas gerais em matéria de legislação tributária apenas no que concerne às limitaçóes constitucionais ao poder de tributar e aos conflitos de competência em matéria tributária; ou se são três campos distintos: dispor sobre as limitações constitucionais, sobre os conflitos de competência e disciplinando as normas gerias em matéria tributária), o fato é que o atual Código Tributário Nacional atende, em grande medida, os incisos I, II e III, letras $a$ e $b$ do art. 146 da CF.

Por outro lado, o inciso III, justamente o que determina que o Congresso Nacional deva dispor, por lei complementar, das normas gerais que disciplinem o adequado tratamento tributário ao ato cooperativo realizado pelas sociedades cooperativas, passados bem mais de trinta anos, ainda não foi atendido. Nesse ponto, tantos os poderes constituídos quanto os órgáos representativos das cooperativas não conseguiram laborar a contento para que a ordem constitucional fosse atendida. Se são diversos os fatos para o estado em que nos encontramos. 
Em primeiro lugar, deve-se registrar o contexto da aprovação do art. 146 da CF. $\mathrm{Na}$ Assembleia Nacional Constituinte, que funcionou no Congresso Nacional de 1986 a 1988, teve a oportunidade de decidir -e não acolheu- o estabelecimento de imunidade tributária para as sociedades. Caso tal proposta tivesse sido aprovada, as sociedades aqui objeto de nossa atenção não recolheriam tributos, assim como, atualmente, não estão sujeitos à tributação ampla os partidos políticos, as igrejas, as sociedades educacionais e assistenciais sem fins lucrativos e os sindicatos de trabalhadores, para ficarmos nos principais beneficiários da imunidade tributária.

Derrotados em não serem submetidos à tributação, o movimento cooperativista brasileiro teve uma vitória muito importante na Assembleia Nacional Constituinte, elevando o tema da complexidade de sua tributação ao nível constitucional, cujo texto exige a já mencionada lei complementar.

Por outro lado, a aprovaçáo de uma lei complementar é, politicamente, mais difícil do que a aprovação das leis ordinárias, pois aquela exige quórum qualificado (metade mais um dos membros de cada uma das duas casas legislativas).

Dois projetos de lei complementar foram apresentados 5 e nenhum prosperou até o momento, além da PEC 110/19 que cria o IVA dentro da proposta de reforma tributária e, regulamenta o Ato Cooperativo. As propostas não são novas.

Aqui, registramos que desconhecemos que as lideranças do cooperativismo nacional tenham conseguido apresentar uma proposta unificadora. E é evidente que, na arena política do Congresso Nacional, a disciplina da tributação é muito sensível e difícil. O Brasil é um país de grandes desigualdades sociais e regionais, além de ser um Estado endividado, principalmente internamente. Assim, reconhecer a adequação da tributação do ato cooperativo pode significar a redução da carga tributária de tais sociedades, com efeitos (ainda que teoricamente falando) na redução da arrecadação dos entes tributantes. Assim, há que se estar preparado para grandes enfrentamentos. De um lado, figurarão os órgãos públicos encarregados da fiscalização e cobrança de tributos (a Receita Federal do Brasil; as 27 secretarias de finanças, uma de cada Estado e a do Distrito Federal; e as $5.500^{6}$ secretarias municipais de finanças). É de se esperar, também, que as sociedades comerciais que concorrem com as cooperativas se posicionem contrariamente a qualquer redução de tributação. Afinal, ainda que nos pareça insustentável, não é impossível supor que, para quem vê as cooperativas como uma ameaça, o adequado tratamento tributário poderia, no extremo, ser visto como uma tributação mais gravosa, que retire o concorrente social que náo se queira.

5. PLC 110/2009 (Senado) e PLC 198/2007 (Câmara dos Deputados).

6. O Brasil possui um modelo federativo único no Brasil, o qual é composto por três entes federados (União, Estados e Municípios), todos independentes e autônomos entre si, o que na prática, significa que não há subordinação e quase nenhuma coordenação entre eles. 
É nesse ambiente de grande embate político que, pelo menos, as sociedades cooperativas precisam estar unidas, apresentando e sustentando no Congresso Nacional um único projeto de lei complementar que atenda ao comando do art. 146, III, $c$ da Carta da República.

Para aumentar a complexidade do desafio aqui apresentado, o Brasil tem discutido, com avanços no máximo tímidos, uma necessária reforma tributária. Nosso sistema constitucional tributário, cujas bases remontam à Emenda Constitucional 01 de 1969, (portanto, ainda sob o comando - apenas formal - da Constituição de 1946), dividiu a competência tributária dos impostos, taxas e contribuição de melhoria entre a União, os Estados, o Distrito Federal e os Municípios, mas acrescentou que a União poderia instituir, também, contribuiçôes - que, a nosso ver, são impostos ou taxas disfarçadas. Para o ponto que aqui interessa, a partir da Constituição de 1988, a Uniāo ficou com os impostos sobre o comércio exterior, sobre produtos industrializados, sobre a renda e sobre operaçóes financeiras, dentre outros; os Estados receberam a competência para instituir e cobrar impostos sobre a circulação de mercadorias e alguns poucos (mas altamente lucrativos) serviços, como o de telecomunicaçóes e transportes intermunicipais e interestaduais - ICMS, e sobre a propriedade de veículos automotores - IPVA; enquanto os municípios ficaram com a tributação dos serviços - ISS e sobre a propriedade urbana - IPTU.

Quanto às contribuiçôes, a União pode instituí-las sobre o domínio econômico, que recebeu uma definição legal que pouco representa as palavras usadas pelo constituinte originário, para sustentar as categorias profissionais e econômicas (Ordem dos Advogados do Brasil e Confederação Nacional das Indústrias, por exemplo) e, principalmente, para o custeio dos serviços públicos assistenciais e previdenciários. Para esse último fim (Seguridade Social), autorizou a tributação sobre faturamento e lucro, v.g. Gerou-se, por fim, sobreposiçôes de tributos sobre a atividade produtiva. Uma indústria, assim, recolherá, dentre outros, Imposto sobre a Produtos Industrializados - IPI, Imposto sobre a Renda da Pessoa Jurídica - IRPJ, Contribuição Social sobre o Lucro Líquido - CSLL, Contribuição para o Programa de Integração Nacional - PIS, Contribuição para o Fundo de Integração Social - COFINS e Imposto sobre Operaçóes Financeiras e de Crédito - IOF. Para dizer o mínimo, IRPJ e CSLL são praticamente iguais, o mesmo se diga do PIS e da COFINS. As semelhanças entre esses quatro tributos mencionados poderiam levar à sua unificação, não fossem questóes federativas que, em uma sociedade altamente dividida (conforme mencionado acima), não se apresentam factíveis no presente.

A Lei das Cooperativas reconheceu que sobre os atos cooperativos não incide imposto sobre a renda. Assim, tais sociedades somente devem recolher o IRPJ e a CSLL sobre os atos não cooperativos. Contudo, não são triviais as disputas com os 
órgãos de fiscalização sobre quais são os atos cooperativos e quais são os atos não cooperativos em cada um dos ramos do cooperativismo praticados no Brasil. E o PIS e a COFINS foram instituídos após a Lei das Cooperativas, que nada poderia disciplinar a seu respeito (BECHO, 2019). Esse debate está sendo travado no Supremo Tribunal Federal, como se verá no próximo item.

Há projetos de emenda constitucional que promovem a reorganização do sistema tributário nacional, unificando, por exemplo, IRPJ, CSLL, PIS, COFINS, IPI, IOF, ICMS e ISS7.

Ainda que o quadro seja extremamente complexo, e ainda mais difícil diante dos diversos tipos de cooperativas e dos atos que podem ser praticados por cada uma delas, o fato é que as lideranças do cooperativismo precisam indicar encontrar respostas palatáveis para questôes básicas, tais como: qual a tributação devida constitucionalmente sobre a produção cooperativada, sobre os resultados positivos da cooperação, sobre a circulação de mercadorias interna (entre a cooperativa e seus associados) e externamente, sobre quais serviços deve a cooperativa, que é uma instituiçẫo prevista por lei para prestar serviços a seus associados, ainda quando haja industrialização.

\section{II.2. Desafios para a Legislação Ordinária}

Os desafios do cooperativismo brasileiro não se limitam às questóes tributárias, existindo uma grande diversidade de temas que merecem atenção do legislador brasileiro. Considerando a limitação espacial deste artigo, nos limitaremos a indicar alguns pontos candentes no Brasil, além da principal questão que é a baixa efetividade das determinaçôes constitucionais, as quais, em diversos momentos, indicam o cooperativismo como estratégia de desenvolvimento brasileiro, porém, nunca foram implementados.

O ponto mais urgente, que talvez resolveria uma série de outras questóes, é referente a uma nova lei geral do cooperativismo. Como demonstrado acima, a lei brasileira está obsoleta, atendendo a interesses econômicos e políticos que sequer existem mais, impedindo o pleno desenvolvimento do cooperativismo, condizente com a Constituição Federal e os novos desafios globais.

Enquanto não há a aprovação desta nova lei, a qual teria condão de ampliar o cooperativismo à novas formas organizativas existentes no Brasil, uma série de questóes ainda estáo à espera de uma maior deliberação pública, tais como: representatividade única do cooperativismo; registro das sociedades cooperativas; sindicalização; cooperativismo de plataforma; falências; ato cooperativo, dentro outros mais.

7. PECs no 45 e 110, na Câmara dos Deputados e no Senado Federal. 


\section{Desafios no Poder Judiciário}

No âmbito do Supremo Tribunal Federal - STF, órgão de cumula do Poder Judiciário brasileiro, com a grande atribuição de ser o guardião da Constituição (CF, art. 92), não são poucos os desafios para as sociedades cooperativas.

Os principais problema do Direito Cooperativo brasileiro em discussão no Poder Judiciária são de natureza tributária. Inicialmente, registramos as longas ações judiciais em que se discutem a incidência de PIS e COFINS sobre as sociedades cooperativas. O STF reverteu as vitórias do cooperativismo no egrégio Superior Tribunal de Justiça - STJ, órgão de terceira instância, com a competência constitucional de unificar a interpretação da legislaçẫo federal dada pelos 27 tribunais de Justiça e das 5 cortes regionais federais.

Além da questão do PIS e COFINS alguma outras questóes ainda estão em aberto no Poder Judiciário brasileiro como o imposto municipal sobre serviços de qualquer (ISSQN), existindo polêmica sobre a incidência deste tributo na relação da cooperativa com consumidores. Esta discussão é decorrente da ausência de uma definição precisa - inclusive pelo Poder Judiciário - do que é ato cooperativo, previsto no art. 79 da lei $5.764 / 71^{8}$.

Também há uma discussão muito grande nos tribunais brasileiros sobre as questôes trabalhistas, não existindo uma definição de qual o limite entre o trabalho cooperado e o trabalho subordinado. O Poder Judiciário trabalhista ainda se encontra em fase de construção destas diferenças, ainda existindo um campo de subjetividade muito grande.

Outras questôes também afligem ramos específicos do cooperativismo, como a incidência do Código de Proteção do Consumidor nas relaçóes entre os cooperados e cooperativas de crédito $(\mathrm{BECHO}, 2009 \mathrm{~b})$. A rápida expansão que o ramo do crédito vem sofrendo no Brasil, avindas das medidas de concentraçáo promovidas pela Lei Complementar 130/2009, será o novo "front" das grandes disputas nos tribunais brasileiros nas próximas décadas e, de forma mais assustadora, sem uma perspectiva animadora de solução. 


\section{Modificaçóes para a solidificação de uma doutrina jurídica cooperativista}

O Direito cooperativo brasileiro se encontra em uma fase de reconstrução.

As últimas grandes teses jurídicas sobre o cooperativismo foram construídas nos anos 60 e 70 do século passado, muitas delas fundamentando a lei atual de cooperativismo que é de 1971. Desde então a doutrina é atualizada porém, sem o surgimento de nenhuma nova tese jurídica sobre o cooperativismo ou, resolver problemas teóricos históricos como, por exemplo, a definição de ato cooperativo.

Este lapso temporal de 50 anos representa um gap geracional - duas geraçóes mais especificamente - de juristas que não pensam mais o cooperativismo. Em outras palavras o conhecimento jurídico dos juristas dos anos 50, 60 e 70 náo foi continuado pela geração seguintes e, consequentemente, transmitido a geração subsequente, razão pela qual, atualmente não se debate o direito cooperativo.

Isto se reflete na ausência de publicaçóes científicas sobre direito cooperativo, organização de eventos científicos ou, mesmo, associaçôes científicas. Nos órgãos de classe, poucas açôes são realizadas. Nas universidades, o quadro é o mesmo, com raríssimas exceçôes, não sendo oferecidas cátedras de direito cooperativo. As pesquisas, realizadas pela pós-graduação são mínimas, existindo poucos pesquisadores ou grupos de pesquisa dedicados ao tema, existindo pouca participação brasileira em organismos e associações internacionais? .

Inexistindo massa crítica, a tarefa de uma grande alteração no direito cooperativo, fica para as próximas geraçôes, devendo a atual geração superar a dificuldade de formação de novos profissionais do direito cooperativo. A superação de questôes estruturais como o ato cooperativo ou, a obrigatoriedade da intercooperação, unicidade de representação, dependem da formação de massa crítica, o que ainda está por vir.

Para isso é essencial o papel das universidades na formação da próxima geração de juristas, seja retomando e reconstruindo o conhecimento já existente sobre direito cooperativo - e introduzindo os novos temas, como a pós-graduação com a descoberta e organização dos temas de fronteira que deverão ser respondidos pelas próximas geraçôes, passando pela extensão, com a atuação junto às cooperativas existentes, em um processo de dupla aprendizagem.

9. Embora o cenário brasileiro não seja animador em termo de geraçáo de conhecimento sobre direito cooperativo - e o cooperativismo em geral - algumas iniciativas promissoras despontam no horizonte, como o recente edital de pesquisa do CNPq/SESCOOP exclusivo para o cooperativismo e que, contemplou vários projetos na área jurídica, o surgimento de algumas teses de doutorado e dissertaçóes de mestrado sobre o tema, especialmente no eixo Rio de Janeiro - Sáo Paulo e, o fortalecimento de associais de pesquisa como a AIDCMESS e o próprio CIRIEC-Brasil. Além disso, diversas obras jurídicas, especialmente coletâneas vem surgindo no Brasil, iniciando um processo de organização do pensamento jurídico nacional, destacando-se também, a forte interação com outros países, especialmente América Latina além de Portugal e Espanha. 
(pp. 327-340)

\section{Referências}

BECHO, R.L. (2019): Tributação das cooperativas. (4a ed.). Revista dos Tribunais.

BECHO, R.L. (2019): Elementos de Direito Cooperativo. (2a ed.). Thomson Reuters - Revista dos Tribunais.

MIRANDA, F.C.P. (1973): Comentários à Constituição de 1967: com a emenda no 1 de 1969. (T. I). Revista dos Tribunais. 